\title{
Postoperative emergence delirium in children: a narrative review of recent publications
}

\author{
Oda Grung Grotmol ${ }^{1, \dagger}$, Narththahi Nesarajah ${ }^{1, \dagger}$, Tom Giedsing Hansen ${ }^{1,2, *}$
}

\author{
${ }^{1}$ Department of Clinical \\ Research-Anesthesiology, Faculty of \\ Health Sciences, University of Southern \\ Denmark, Odense, Denmark \\ ${ }^{2}$ Department of Anesthesiology and \\ Intensive Care, Odense University \\ Hospital, Odense, Denmark

\section{*Correspondence} \\ tomghansen@dadlnet.dk \\ (Tom Giedsing Hansen) \\ $\dagger$ These authors contributed equally.
}

\begin{abstract}
Background: Emergence delirium is a challenge in pediatric anesthesiology, with important unanswered questions concerning incidence, causation, diagnosis, treatment, and sequelae. In this review, we will present the recent research with a particular focus placed on treatment and prevention options.

Methods: A wide literature search was conducted across MEDLINE and other databases using PubMed, Embase, Ovid, and the Cochrane Library (latest access: 23 November 2020). The collected publications were assessed for relevance. Only randomized controlled trials and observational studies on postoperative emergence delirium in children were included. Exclusion criteria were articles published before 2018, and studies comprising children older than 12 years of age, mental retardation, or chronic diseases.

Results: The final number of studies included in this review was 44 . Risk factors identified for emergence delirium were volatile inhalation anesthetics, young age, child temperament, preoperative anxiety, male gender, and specific surgical procedures. Preventive and/or intervention measures were pharmacological (e.g. TIVA, $\alpha_{2}$-adrenergic agonists (particularly dexmedetomidine), ketamine, propofol, midazolam, opioids (fentanyl)) and non-pharmacological measures (e.g. video or tablet distraction, familiarization with the operating environment, use of mother's voice, visual preconditioning in eye surgery).

Conclusion: ED should be considered a "vital sign" and recorded and documented in all children in the PACU. There is an urgent need for future research to fill in missing gaps of knowledge regarding ED. Implementation of a standardized and validated screening tool for ED are high priorities as is the impact of perioperative monitoring of children at risk to prevent ED.
\end{abstract}

\section{Keywords}

General anesthesia; Children; Post-anesthesia behavior; Emergence delirium; Emergence agitation; Pharmacology; Anesthetics

\section{Introduction}

Within the field of pediatric anesthesia, postoperative emergence delirium (ED) remains an area with room for improvement. Questions unanswered concern causation, incidence, prevention, optimal treatments, and long-term prognosis. In this article, we present the recent research on this topic, in light of previous knowledge with a particular focus placed on pharmacological and non-pharmacological treatment and prevention options.

The definition of ED sometimes also referred to as Emergence Agitation (EA) is "an alteration in consciousness manifesting as disorientation, averted eyes or staring, psychomotor agitation and hyperactivity or non-purposefulness" [1]. It may present within the first 45 min after cessation of anesthesia and usually lasts for 15-20 minutes. The phenomenon may occur in both children and adults, however with an increased incidence in young children and the elderly [2]. Although the terms ED and EA are often used interchangeable, it is important to emphasize that ED is not fully similar to EA. Because ED can also comprise hypoactive signs or mixed forms and hyperactive signs or agitation. The challenge is to separate ED and EA from pain, and from postoperative delirium [2].

The choice of tool to diagnose ED is a topic of controversy, as it affects the assessment of incidence-reported to range from $10 \%-80 \%$ [3]. Predisposing factors include inhalational (sevoflurane) anesthesia, young age of the child, preoperative anxiety, child temperament, male gender [2], and certain specific surgical intervention, e.g. ophthalmology and oto-rhinolaryngology surgeries [3]. Emergence delirium may result in unnecessary harm to the child and frightening of parents, as well as disturbing other patients present in the Post Anesthetic 
Care Unit (PACU) and be associated with long-term sequelae [1-3].

\section{Method}

A search was conducted across MEDLINE and other databases using PubMed, Embase, and the Cochrane Library (Latest access on 23 November 2020). The following keywords and search terms, including their corresponding synonyms, were used to retrieve articles according to standard PICOS (population, intervention, comparison, outcome, study design) criteria: child [MeSH], paediatrics [MeSH], anaesthetic drugs [MeSH] or anaesthetic effect [MeSH] postoperative behaviour [MeSH], emergence delirium or agitation [MeSH], randomised controlled trial [MeSH], observational study [MeSH]. Studies published before 2018 were screened but only studies published after 2018 were included in the actual review process. Randomized clinical trials and observational studies comprising children younger than 12 years who received general anesthesia were included. All studies comprising children with mental retardation, cancer, and chronic lung, heart, or kidney disease were excluded. Articles written in other languages than English were also excluded. Besides, papers of impact found through references in these were reviewed and included if relevant.

\section{Results}

The selection process resulted in the inclusion of 44 original research articles (Fig. 1).

\section{Background}

\subsection{Assessment of emergence delirium}

Many scales have been used to identify ED. The limitations of the majority of these are that they have not been psychometrically tested and that they follow emotional stress and psychomotor agitation as a surrogate for delirium.

\subsubsection{PAED scale}

In 2004, Sikich and colleagues developed the Pediatric Anesthesia Emergence Delirium (PAED) scale to assess the incidence of ED in children $>2$ years of age [4] (Table 1). This scale has been psychometrically validated and is considered to be a relatively reliable and accurate tool to diagnose ED in children. The scale consists of five items. The first and third reflect changes in the child's consciousness-the third item more specifically addresses cognition. The second, fourth, and fifth items evaluate disturbance in psychomotor behavior and emotion. Importantly, the last two items may, in addition to ED, reflect symptoms of pain, stress, and discomfort. A high PAED score is indicative of ED.

The scale has been assessed for inter-observer reliability (0.84; 95\% CI: $0.76-0.90)$, sensitivity (0.64), and specificity (0.14), given a threshold value of $\geq 10$ for the diagnosis of ED [4]. The appropriate PAED scale threshold for defining ED remains unclear. A recent study found that the incidence of ED varies between $17.2 \%-29.5 \%$, depending on a scale threshold value $(\geq 10,>12$ or $\geq 16)$ [5]. Furthermore, the
TA B L E 1. Paediatric anaesthesia emergence delirium (PAED) scale.

\begin{tabular}{l|c|c|c|c|c} 
Behaviour & $\begin{array}{l}\text { Not } \\
\text { at } \\
\text { all }\end{array}$ & $\begin{array}{l}\text { Just } \\
\text { a } \\
\text { little }\end{array}$ & $\begin{array}{l}\text { Quite } \\
\text { a bit }\end{array}$ & $\begin{array}{l}\text { Very } \\
\text { much }\end{array}$ & Extremely \\
\hline $\begin{array}{l}\text { 1. The child } \\
\text { makes eye } \\
\text { contact with } \\
\text { the caregiver. }\end{array}$ & 4 & 3 & 2 & 1 & 0 \\
\hline $\begin{array}{l}\text { 2. The child's } \\
\text { actions are } \\
\text { purposeful. }\end{array}$ & 4 & 3 & 2 & 1 & 0 \\
\hline $\begin{array}{l}\text { 3. The child } \\
\text { is aware of } \\
\text { his/her } \\
\text { surroundings. }\end{array}$ & 4 & 3 & 2 & 1 & 0 \\
\hline $\begin{array}{l}\text { 4. The child } \\
\text { is restless. }\end{array}$ & 0 & 1 & 2 & 3 & 4 \\
\hline $\begin{array}{l}\text { 5. The child } \\
\text { is } \\
\text { inconsolable. }\end{array}$ & 0 & 1 & 2 & 3 & 4 \\
\hline
\end{tabular}

Note that items 1, 2 and 3 are scored from 4-0, while items 4 and 5 are scored reversely from 0-4. A higher score correlates with a higher degree of ED. Usually; a threshold value is set for diagnosis.

study confirmed an acceptable degree of inter-rater reliability, thus, supporting the use of the PAED scale for the diagnosis of ED.

The PAED scale is currently the most widely used tool for the assessment of ED in scientific research. However, there are limitations when using the scale. The subjective nature of some assessments, relatively high inter-rater variability, high false-positive rate and qualifying behavior which overlap with pain. Furthermore, there is a lack of consensus regarding which threshold value to apply, which makes it difficult to compare scientific data. Given pain is a confounding factor with the PAED scale, the incidence of ED will undoubtable be influenced e.g. type of surgery and analgesics administered.

\subsubsection{Aono's four-point scale}

Aono's four-point scale, developed in 1997, is another tool currently used to assess ED in children (Table 2) [6]. Its main limitation is a profound lack of ability to differentiate between ED and pain.

\subsubsection{Other scales}

Emergence delirium in children is also diagnosed by employing other scales, though not validated. Among these, are the Cravero and the Watcha scales, commonly used in clinical settings due to their simplicity. They both correlate well with results obtained with the PAED scale [7]. The Cravero scale is scored as $1=$ obtunded with no response to stimuli, $2=$ Asleep, but responsive to movement and stimuli, $3=$ Awake and appropriately responsive, $4=$ Crying and difficult to console, and $5=$ Wild thrashing behavior that requires restraint. Here, 4 and 5 are indicative of ED. In the Watcha scale, patient behavior is scored as $0=$ Asleep, $1=$ Calm, $2=$ Crying, but can 


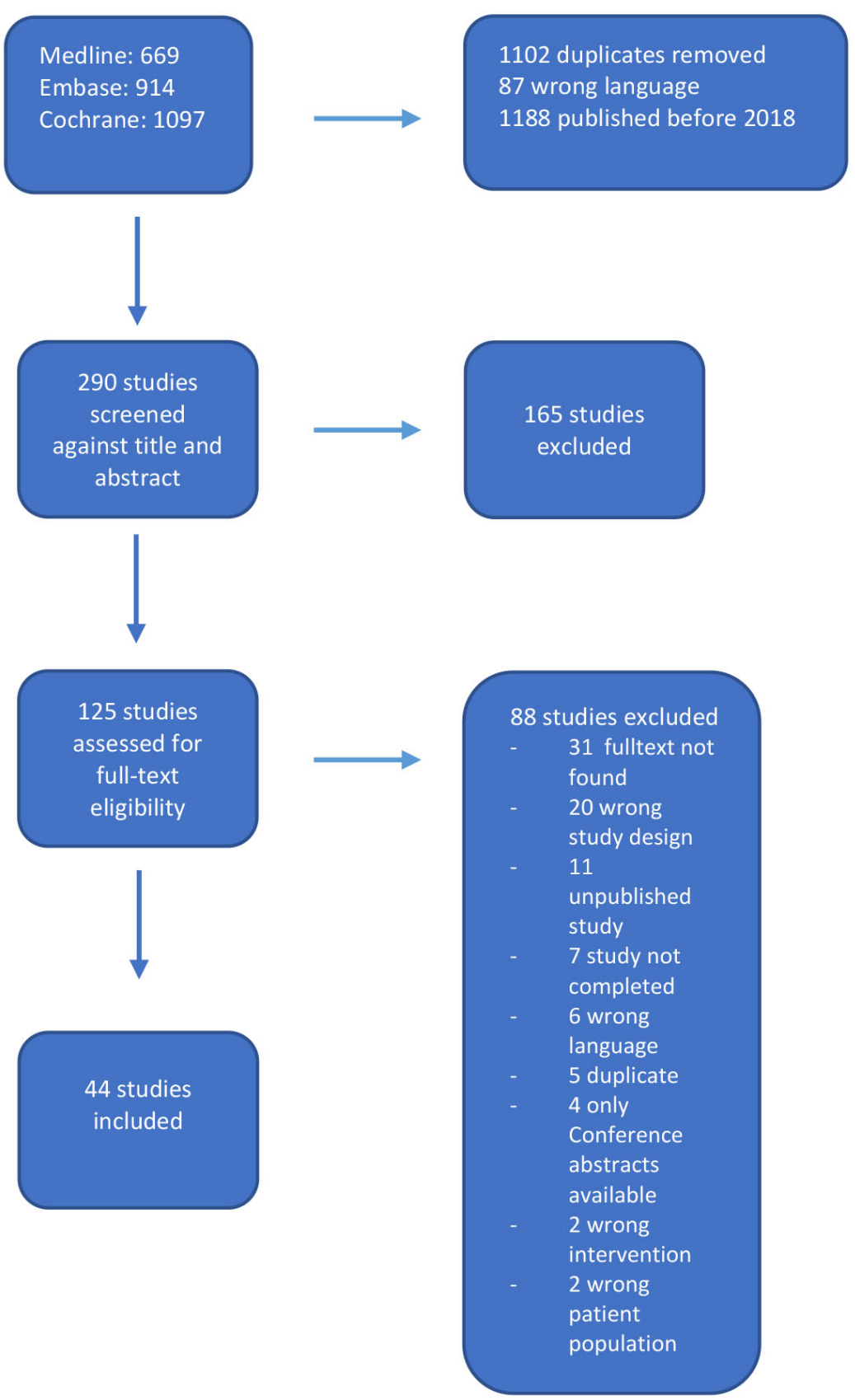

F I G URE 1. Flowchart of the articles selection process.

TA B LE 2. Aono's four-point scale.

\begin{tabular}{l|l} 
Score & Behaviour \\
\hline $\mathbf{1}$ & Calm \\
\hline $\mathbf{2}$ & Not calm but could easily be calmed \\
\hline $\mathbf{3}$ & Not easily calmed, moderately agitated or restless \\
\hline $\mathbf{4}$ & Combative, excited or disoriented \\
\hline
\end{tabular}

be consoled, 3 = Crying, but cannot be consoled, 4 = Agitated, and thrashing around. The scale defines ED to be present at scores 3 and 4 .

The Objective Pain Score (OPS) [8] (Table 3), mainly used for the evaluation of pain, has also been used in studies on
ED. The Richmond Agitation and Sedation Scale (RASS) [9] (Table 4) and The Cole 5-point scale (CPS) [10], have both been used for the assessment of ED. The CPS is scored as 1 = sleeping, 2 = awake, calm, $3=$ irritable, crying, $4=$ inconsolable crying, $5=$ severe restlessness, disorientation. 
TA B L E 3. The Objective Pain Score (OPS).

\begin{tabular}{|c|c|c|}
\hline Parameters & Criteria & Score \\
\hline \multirow[t]{3}{*}{ Systolic blood pressure } & $\begin{array}{l}\text { Increase }<20 \% \text { of } \\
\text { preoperative blood pressure }\end{array}$ & 0 \\
\hline & $\begin{array}{l}\text { Increase } 20 \% \text { to } 30 \% \text { of } \\
\text { preoperative blood pressure }\end{array}$ & 1 \\
\hline & $\begin{array}{l}\text { Increase }>30 \% \text { of } \\
\text { preoperative blood pressure }\end{array}$ & 2 \\
\hline \multirow[t]{3}{*}{ Crying } & Not crying & 0 \\
\hline & $\begin{array}{l}\text { Responds to age } \\
\text { appropriate nurturing } \\
\text { (tender loving care) }\end{array}$ & 1 \\
\hline & $\begin{array}{l}\text { Does not respond to } \\
\text { nurturing }\end{array}$ & 2 \\
\hline \multirow[t]{3}{*}{ Movements } & No movements, relaxed & 0 \\
\hline & $\begin{array}{l}\text { Restless, moving about in } \\
\text { bed constantly }\end{array}$ & 1 \\
\hline & Thrashing (moving widely) & 2 \\
\hline \multirow[t]{3}{*}{ Agitation } & Asleep or calm & 0 \\
\hline & $\begin{array}{l}\text { Can be comforted to lessen } \\
\text { the agitation (mild) }\end{array}$ & 1 \\
\hline & $\begin{array}{l}\text { Cannot be comforted } \\
\text { (hysterical) }\end{array}$ & 2 \\
\hline \multirow[t]{4}{*}{ Complains of pain } & Asleep & 0 \\
\hline & States no pain & 0 \\
\hline & Cannot localize & 1 \\
\hline & Localizes pain & 2 \\
\hline
\end{tabular}

\subsection{Pain scales for younger children}

The FLACC scale is a behavioral pain assessment scale used to evaluate pain in children aged 2 months to 7 years or other individuals (including adult patients in intensive care units) who are unable to communicate their pain. The scale is scored in a range of $0-10$ with 0 representing no pain. The scale has five criteria (Face, Legs, Activity, Cry, and Consolability), which are each assigned a score of 0,1 , or 2 [11]. A similar behavioral pain assessment scale is the CHEOPS (Children's Hospital of Eastern Ontario Pain Scale) for children aged 1-7 years. The scale has six different categories of pain behavior (cry, facial, verbal, torso, touch, and legs). A score ranging from 0 to 2 or 1 to 3 is assigned to each of these with a total score ranging between 4 and 13 [12]. The cut-off point for the FLACC is $<3$ and the CHEOPS $<6$; values above these are considered as the presence of pain. The sensitivity and specificity of the FLACC scale are higher than those of the CHEOPS.

\subsection{Comments}

All the above-listed scales have many shortcomings. Either they are somewhat too complicated to be used in a busy clinical setting, or they are too simple to be able to address ED/EA properly. Importantly, it has been demonstrated that issues such as "no eye contact" and "no awareness of surroundings" are indicative for $\mathrm{ED}$, whereas "abnormal facial expression" and "crying and inconsolability" indicate acute pain in the immediate postoperative period [13].

\subsection{Impact of general anesthesia}

As previously mentioned, ED is more common following inhalation anesthesia (particularly sevoflurane) than following total intravenous anesthesia (TIVA). A meta-analysis of data comprising 1100 children from 14 randomized clinical trials concluded that ED had a lower incidence after general anesthesia with propofol than with sevoflurane (pooled odds ratio $=0.25$; $95 \%$ CI: $0.16-0.39, P=0.0000$ ) [14]. Another metaanalysis, comprising 4 non-randomized and 154 randomized clinical trials and a total of 14,045 children came to a similar conclusion; i.e. ED occurred less frequently after propofol than sevoflurane $(\mathrm{RR}=0.35 ; 95 \% \mathrm{CI}: 0.25-0.51 ; 1098$ participants $)$ [15]. Currently, it is unknown why the risk of ED is higher after sevoflurane anesthesia compared with all other anesthetic agents. It was initially speculated to be caused by the newer inhalational agents having lower blood-gas solubility coeffi- 
TA B L E 4. The Richmond Agitation and Sedation Scale (RASS).

\begin{tabular}{|c|c|c|}
\hline Score & & Description \\
\hline+4 & Combative & $\begin{array}{l}\text { Violent, immediate danger } \\
\text { to staff }\end{array}$ \\
\hline+3 & Very agitated & $\begin{array}{l}\text { Pulls at or removes tubes, } \\
\text { aggressive }\end{array}$ \\
\hline+2 & Agitated & $\begin{array}{l}\text { Frequent non-purposeful } \\
\text { movements, fights } \\
\text { ventilator }\end{array}$ \\
\hline+1 & Restless & $\begin{array}{l}\text { Anxious, apprehensive but } \\
\text { movements not aggressive } \\
\text { or vigorous }\end{array}$ \\
\hline 0 & Alert and calm & \\
\hline-1 & Drowsy & $\begin{array}{l}\text { Not fully alert, sustained } \\
\text { awakening to voice (eye } \\
\text { opening and contact }>10 \text { s) }\end{array}$ \\
\hline-2 & Light sedation & $\begin{array}{l}\text { Briefly awakens to voice } \\
\text { (eye opening and contact } \\
<10 \text { s) }\end{array}$ \\
\hline-3 & Moderate sedation & $\begin{array}{l}\text { Movement or eye-opening } \\
\text { to voice (no eye contact) }\end{array}$ \\
\hline-4 & Deep sedation & $\begin{array}{l}\text { No response to voice, but } \\
\text { movement or eye opening } \\
\text { to physical stimulation }\end{array}$ \\
\hline-5 & Unarousable & $\begin{array}{l}\text { No response to voice or } \\
\text { physical stimulation }\end{array}$ \\
\hline
\end{tabular}

cients, resulting in faster emergence. However, this does not seem to be the case. Exposed to rapid emergence, the number of children experiencing ED was still six times lower with propofol anesthesia (4\%) compared to sevoflurane (24\%) [16]. Similarly, in a recent study using sevoflurane where children were randomly assigned to abrupt discontinuation or gradual emergence, the incidence of ED was not significantly different [17].

Recently, a randomized, clinical trial was conducted to correlate the effect of sevoflurane anesthesia and Total Intravenous Anaesthesia (TIVA) with propofol on emergence delirium and recovery characteristics. This study included children (3-7 yrs) under general anesthesia for outpatient dental treatment. The PAED scale was used to assess ED. There was a significant difference between the two groups, where $65.5 \%$ of the children administered sevoflurane developed ED, compared to $3.4 \%$ in the TIVA group $(P=0.000)$ [18].

\subsection{Impact of surgery and interventions}

Some surgeries have a higher incidence of ED than others. In a prospective cohort study by Voepel-Lewis and co-workers [19], a higher incidence of ED was found in children undergoing otorhinolaryngology $(26 \%$; relative risk $=1.69 ; 95 \%$ CI: $1.2-2.4 ; P=0.004)$ and ophthalmology $(28 \%$; relative risk $=1.66 ; 95 \% \mathrm{CI}: 1.1-2.5 ; P=0.017)$ surgery compared to orthopaedic $(15 \%)$, urological $(15 \%)$, and general surgery $(12 \%)$.

\subsection{Preventive measures}

Although commonly used for general anesthesia in pediatrics, volatile inhalational anesthetics such as sevoflurane and desflurane are associated with a high incidence of ED [15, 20]. Minimizing the utilization of these in favor of TIVA with propofol would therefore constitute a major preventive measure, as well as minimizing the use of mask induction whenever possible and use IV induction.

Perioperative drugs can also help in lowering the incidence of ED. For instance, administration of IV propofol, midazolam, opioids, or $\alpha_{2}$-adrenergic receptor agonists (particularly dexmedetomidine) may be beneficial. Changing agent dose, route or perioperative timing of administration may lead to contradicting results. Strategies chosen, vary among clinicians $[21,22]$, and are of international controversial discussion. A range of different perioperative agents recently studied as means of ED prevention are listed in Table 5.

\section{Pharmacological interventions}

Although ED is mainly self-limiting, it may in some cases require pharmacological treatment. Few studies have systematically addressed treatment strategies. Current knowledge regarding the optimal management of $\mathrm{ED}$ is thus incomplete. This is reflected in the large variety of pharmacological agents used - e.g. propofol, midazolam, fentanyl, morphine, and dexmedetomidine [21]. 
T A B L E 5. Effective and ineffective drugs used to prevent ED.

\begin{tabular}{|c|c|c|}
\hline Effective medication & Dosage & Route/timing of administration \\
\hline Propofol & $\begin{array}{l}3 \mathrm{mg} / \mathrm{kg} \\
2 \mathrm{mg} / \mathrm{kg}\end{array}$ & $\begin{array}{l}\text { I.V./End of surgery } \\
\text { I.V./End of surgery }\end{array}$ \\
\hline Midazolam & $\begin{array}{l}0.04 \mathrm{mg} / \mathrm{kg} \\
0.03 \mathrm{mg} / \mathrm{kg}\end{array}$ & $\begin{array}{l}\text { I.V./End of surgery } \\
\text { I.V./End of surgery }\end{array}$ \\
\hline Remifentanil & $0.05 \mu \mathrm{g} / \mathrm{kg} / \mathrm{min}$ & I.V./Intra/postoperative \\
\hline Nalbuphine & $0.1 \mathrm{mg} / \mathrm{kg}$ & I.V./30 min before end of surgery \\
\hline Dexmedetomidine & $\begin{array}{l}2 \mu \mathrm{g} / \mathrm{kg} \\
4 \mu \mathrm{g} / \mathrm{kg} \\
1 \mu \mathrm{g} / \mathrm{kg} \\
0.5 \mu \mathrm{g} / \mathrm{kg} \\
0.2 \mu \mathrm{g} / \mathrm{kg} / \mathrm{hour}\end{array}$ & $\begin{array}{l}\text { P.O./Premedication } \\
\text { P.O./Premedication } \\
\text { I.V./Premedication } \\
\text { I.V./Intraoperative } \\
\text { I.V./Intraoperative }\end{array}$ \\
\hline Gabapentin & $5 \mathrm{mg} / \mathrm{kg}$ & P.O./Premedication \\
\hline Esmolol and Lidocaine & $\begin{array}{l}0.5 \mathrm{mg} / \mathrm{kg} \text { (Esmolol) } \\
1.5 \mathrm{mg} / \mathrm{kg} \text { (Lidocaine) }\end{array}$ & $\begin{array}{l}\text { I.V.I voluntary movement (Esmolol), } \\
\text { End of surgery (Lidocaine) }\end{array}$ \\
\hline Ineffective medication & Dosage & Route/timing of administration \\
\hline Ondansetron & $100 \mathrm{mg} / \mathrm{kg}$ & I.V./Intraoperative \\
\hline Midazolam & $0.01 \mathrm{mg} / \mathrm{kg}$ & I.V./Premedication \\
\hline Ketofol & $\begin{array}{l}25 \mu \mathrm{g} / \mathrm{kg} / \mathrm{min} \text { (Ketamine) } \\
75 \mu \mathrm{g} / \mathrm{kg} / \mathrm{min} \text { (Propofol) }\end{array}$ & TIVA \\
\hline
\end{tabular}

\subsection{Propofol}

In addition to its use in TIVA, propofol may be administered at the end of sevoflurane anesthesia to prevent ED. In a prospective randomized controlled trial, children (1-12 yrs) who received general anesthesia for magnetic resonance imaging were randomized to receive either propofol $3 \mathrm{mg} / \mathrm{kg}$ over 3 minutes or no propofol at the end of anesthesia. In the propofol group, a significantly lower incidence of ED was observed, using two different scales: PAED (29\% vs $7 \% ; P$ $<0.001)$ and Watcha (39\% vs $15 \% ; P<0.001)$ [23]. These findings have been confirmed in a recent study where the infusion of $3 \mathrm{mg} / \mathrm{kg}$ propofol over three minutes also was found to reduce ED frequency [24]. Furthermore, a study with an IV propofol administration of $2 \mathrm{mg} / \mathrm{kg}$ near the end of sevoflurane anesthesia also reported a significant decrease in the incidence of ED, measured by PAED scale $(5.66 \pm 1.74$ vs $9.87 \pm 3.15 ; P$ $<0.01$ ) [25]. Fewer adverse events of the gastrointestinal tract and respiratory response $(5 \%$ vs $13.75 \% ; P=0.03)$ were also found. It may be noted that results are given as mean PAED score, which does not necessarily correlate with ED incidence that is defined by a score threshold value.

On the other hand, IV administration of a lower dose of propofol $(1 \mathrm{mg} / \mathrm{kg})$ towards the end of sevoflurane anesthesia may not be sufficient to reduce ED incidence. Here, two similar studies present contradicting results [26, 27] - one shows the preventive effect, the other not. However, the recovery time might be some-what prolonged if propofol is administered at the end of the procedure.

\subsection{Midazolam}

It has been researched whether the benzodiazepine midazolam may attenuate ED incidence. Studies show that the route, dosage, and timing of midazolam administration give different results. Used as rectal premedication, it does not affect ED frequency [28]. A recent study investigated the efficacy of an IV bolus of $0.01 \mathrm{mg} / \mathrm{kg}$ midazolam for premedication in children aged 1-6 years undergoing cochlear surgery. No effects on ED were found [29]. In contrast, IV midazolam $(0.03 \mathrm{mg} / \mathrm{kg})$ administered at the end of surgery reduced the incidence of ED compared with saline. (PAED scale; $17 \%$ vs $43 \% ; P=0.036)$ [30]. Another study compared the effect of midazolam $(0.04 \mathrm{mg} / \mathrm{kg})$ to propofol $(0.8 \mathrm{mg} / \mathrm{kg})$ infusion five minutes before the cessation of sevoflurane anesthesia [31]. Midazolam was found to be superior to propofol in preventing sevoflurane-induced ED, though it may be noted that the study did not include a control group and that the propofol dosage was low.

\subsection{Opioids}

ED may also be prevented by the use of opioids, e.g. intraoperative IV remifentanil $(0.05-0.15 \mu \mathrm{g} / \mathrm{kg} / \mathrm{minute})$ or intranasal or IV fentanyl $(0.5-1 \mu \mathrm{g} / \mathrm{kg})$ [32]. A very recent study has investigated whether a continuation of low-dose remifentanil $(0.05 \mu \mathrm{g} / \mathrm{kg} / \mathrm{min})$ administered throughout the recovery phase of sevoflurane anesthesia can affect the incidence of ED. Remifentanil was administered until specific discharge criteria were met (modified Aldrete post-anesthesia recovery score $>9)$. The authors found a significant reduction of ED incidence using The Cole five-point scale $(33.3 \%$ vs $68.3 \%$; $P$ $=0.002)$ and PAED scale for scores $>12(5.1 \%$ vs $34.0 \% ; P=$ $0.001)$, while length of stay in the PACU remained similar to the control group [33].

Another recent study evaluated the effects of IV Nalbuphine on ED in children (3-6 yrs) under Sevoflurane anesthesia. ED was measured using Aono's four-point scale and PAED scale. Patients in the Nalbuphine group had a significantly lower ED score compared to the control group (Aono's scale: $21.43 \%$ vs 
57.14\%; PAED scale: $21.43 \%$ vs $54.76 \%$; both $P<0.01$ ) [34].

The above studies showed a lower incidence of ED in patients receiving opioids, compared to control groups, which supports the notion that pain may contribute to the development of ED.

\section{$5.4 \alpha_{2}$-adrenergic receptor agonists}

A study where dexmedetomidine was administered as oral premedication $(1 \mu \mathrm{g} / \mathrm{kg})$ before sevoflurane anesthesia did not show an attenuation of ED incidence [35]. Two recent studies have compared oral dexmedetomidine in higher doses $(2 \mu \mathrm{g} / \mathrm{kg}$ and $4 \mu \mathrm{g} / \mathrm{kg}$, respectively) to oral midazolam $(0.5 \mathrm{mg} / \mathrm{kg})$ as premedication $[36,37]$. They both used the PAED scale to assess ED incidence, and both studies found Dexmedetomidine to be superior to Midazolam in preventing ED $(P<0.05$ and $P=0.000$, respectively). Another recent study looked at a different administration route - IV infusion of Dexmedetomidine $(1 \mu \mathrm{g} / \mathrm{kg}$ ) over ten minutes before induction of anesthesia to prevent ED. The PAED score showed a significantly lower ED incidence $(P<0.001)$ [38]. Intraoperative Dexmedetomidine has also been used as a preventative measure in two recent studies. In one of them, $0.5 \mu \mathrm{g} / \mathrm{kg}$ was administered IV over ten minutes after anesthesia induction, which resulted in significantly lower ED incidence compared to saline control (31.1\% vs $53.3 \% ; P=0.033$ ) [39]. In the other study, a continuous IV infusion of $0.2 \mu \mathrm{g} / \mathrm{kg} /$ hour was administered after induction of anesthesia until the end of the surgery, which reduced incidence of ED markedly, measured by OPS $(15.0 \%$ vs $82.5 \% ; P<0.001$ ) [40]. A recent systematic review suggested that dexmedetomidine may be the drug of choice in preventing ED/EA [41].

\subsection{Regional anaesthesia}

The use of regional anesthesia has been shown to have an impact on ED incidence, even more so than opioids. A randomized controlled, observer-blind study examined the effect of regional pain relief through brachial plexus block (BPB) versus opioid on children 2-7 years of age, undergoing humerus fracture surgery with sevoflurane anesthesia. The BPB group was given a nerve block with $0.2 \%$ ropivacaine $(0.5 \mathrm{~mL} / \mathrm{kg})$, and the opioid group was administered $1 \mu \mathrm{g} / \mathrm{kg}$ of IV fentanyl at 2-3 min before incision or pinning, $0.5 \mu \mathrm{g} / \mathrm{kg}$ of IV fentanyl at $5 \mathrm{~min}$ before the end of surgery. The PAED scale score was found to be significantly lower in the BPB group compared to the opioid group, as well as the incidence of ED [42].

Another study has compared peri-bulbar block $(0.3 \mathrm{~mL} / \mathrm{kg}$ of $0.25 \%$ bupivacaine $+2 \%$ lignocaine) to opioid (fentanyl $2 \mu \mathrm{g} / \mathrm{kg}$ ) in children 2-10 years old undergoing strabismus surgery. The anesthesia was induced by sevoflurane and maintained by desflurane. Incidence and severity of ED, measured by the PAED score, was significantly attenuated in the block group compared to the fentanyl group [43].

The addition of dexmedetomidine to a nerve block has also been studied. Children 2-7 years old undergoing vitreoretinal surgery were divided into three groups: one receiving retrobulbar $0.5 \%$ ropivacaine $0.1 \mathrm{~mL} / \mathrm{kg}+$ dexmedetomidine $1 \mu \mathrm{g} / \mathrm{kg}$ (RD group), the other a ropivacaine-only block of the same dose (RB group), and the third was administered IV remifentanil $0.1 \mu \mathrm{g} / \mathrm{kg} / \mathrm{min}$ (F group) and operated without a nerve block. All three groups received propofol for anesthesia induction and maintenance. The study found a significant difference in ED prevalence, being the lowest in the RD group, followed by the RB group and with the highest number in the F group. Also, the need for intraoperative rescue fentanyl and postoperative pain scores were lower in the RD group [44].

\subsection{Magnesium sulfate}

The effect of intraoperative magnesium sulfate on the incidence and severity of ED was studied in children undergoing adenotonsillectomy under sevoflurane anesthesia [45]. Children in the intervention group received an IV loading dose of $30 \mathrm{mg} / \mathrm{kg}$ over 10 minutes, which was followed by continuous infusion of $10 \mathrm{mg} / \mathrm{kg}$ during the whole surgery. Patients in the control group received the same amount of saline. Using PAED scale, the intervention group showed a significantly lower ED incidence, compared to the control group (36\% vs $72 \% ; P=0.004)$. Further research on the use of magnesium sulfate to prevent ED is needed.

\subsection{Melatonin}

Kain and colleagues [46] conducted a randomized controlled trial in 2009 to investigate the effects of melatonin on ED prevention. The children (3-7 yrs) were divided into groups receiving different oral melatonin dosages $(0.05 \mathrm{mg} / \mathrm{kg}, 0.2$ $\mathrm{mg} / \mathrm{kg}$, and $0.4 \mathrm{mg} / \mathrm{kg}$, respectively) as premedication. A fourth group received $0.5 \mathrm{mg} / \mathrm{kg}$ of oral midazolam. The study results showed that the incidence of ED was highest in the midazolam group $(25.6 \%)$, whereas in the melatonin groups the incidence of ED was markedly decreased following an increase in the dose $(25 \%, 8.3 \%$, and $5.4 \%$, respectively; $P$ $<0.05)$. Studies comprising melatonin in higher doses are underway.

\subsection{Ketamine}

It has previously been stated that children undergoing strabismus surgery and anesthetized with sevoflurane had a lower incidence of ED when they additionally received Ketamine 1 $\mathrm{mg} / \mathrm{kg}$ IV followed by an infusion at $1 \mathrm{mg} / \mathrm{kg} /$ hour [47]. A recent study comprising 3-12 years old children undergoing tonsillectomy has compared IV propofol (100 $\mu \mathrm{g} / \mathrm{kg} / \mathrm{min})$ and IV ketofol (ketamine $25 \mu \mathrm{g} / \mathrm{kg} / \mathrm{min}$ and propofol $75 \mu \mathrm{g} / \mathrm{kg} / \mathrm{min}$ ) anesthesia concerning ED. The incidence and severity of ED were measured by PAED score. Interestingly, no statistical difference could be found [48].

\subsection{Gabapentin}

This anti-epileptic agent gabapentin also used to treat neuropathic pain, has recently been investigated for a possible effect on ED incidence. Badawy and colleagues [49] gave oral gabapentin $(5 \mathrm{mg} / \mathrm{kg})$ as premedication to children (2-6 yrs), undergoing strabismus surgery, and compared it to placebo. Desflurane anesthesia was employed. Their study found a $20 \%$ reduction in the incidence of ED in the gabapentinpremedicated group, using the Cravero scale $(P=0.006)$. 


\subsection{Ondansetron}

It has been investigated whether ondansetron, a serotonin 5HT3 receptor antagonist and commonly used antiemetic drug, can reduce the incidence of emergence delirium. An administration of IV ondansetron $(100 \mu \mathrm{g} / \mathrm{kg})$ after induction of sevoflurane anesthesia did not significantly impact the incidence of ED (measured by the PAED scale in 2-12 years old children undergoing strabismus surgery) [50].

\subsection{Miscellaneous}

A trial hypothesized that the frequency of ED would be reduced by the use of esmolol, an adrenergic $\beta-1$ receptor antagonist with sedative effects. It also investigated the effect of IV lidocaine, a local anesthetic that may reduce airway responsiveness, as well as a combination of the two. Emergence delirium was measured using OPS, CPS, and RASS. The group where esmolol and lidocaine were combined had a lower incidence of ED, compared to the other groups, including the saline control group [51]. Compared to succinylcholine the use of rocuronium/sugammadex reduced the incidence, severity, and duration of ED in adults (including teenagers) undergoing reduction of nasal fractures [52].

\section{Non-pharmacological interventions}

\subsection{Perioperative anxiety reduction}

A possible effect of perioperative anxiety on ED in children has been addressed by several researchers. Two separate studies conducted in 2004 and 2006 both showed a significant positive correlation between preoperative anxiety and ED [53, 54]. They used the modified Yale Preoperative Anxiety Scale (mYPAS) immediately before anaesthesia. Berghmans and colleagues [49], using the Child Behavior Check List (CBCL) to assess behavior over the 6 months prior to operation, found no connection between longer term anxiety behavior and ED assessed using the PAED scale. Thus, it remains unclear whether preoperative anxiety is related to ED incidence in pediatric patients. In addition to medical anxiolytics, several non-medical means of perioperative anxiety reduction have been tested.

\subsection{Mother's voice during emergence}

Several studies have investigated the effects of listening to the mother's recorded voice during emergence compared to a stranger's voice. One trial investigated the effect of a mother's recorded voice compared to a stranger's voice at the end of the operation. The recorded voice was delivered to the child by noise-canceling headphones. This was continued until the arrival of the patient to the PACU and ED was measured using both the PAED scale and Watcha scale. This trial revealed that the incidence of ED during PACU stay was significantly lower in children (2-8 yrs) listening to their mother's voice compared to children listening to a stranger's voice $(P=0.006)$ [55]. These findings have recently been confirmed [56].

\subsection{Interactive distraction}

A review of studies using video for distraction published between 2005 and 2017 showed a reduction in preoperative anxiety but little evidence of ED reduction [57]. However, a study published in 2019 [58] compared the effect of oral midazolam premedication with the effect of tablet-based interactive distraction (TBID). The PAED scale was used to assess ED. There was no significant difference between the groups regarding the mean total PAED scores. Despite this, the PAED score measured at 15 minutes after awakening was significantly lower in the TBID group, compared to the midazolam group $(P=0.001)$. The use of video for distraction is emerging, but so far only reduces preoperative anxiety and not ED [58].

\subsection{Preoperative visit to the operating room}

The unfamiliarity of the operating theatre can give anxiety. A prospective, randomized controlled trial [59] was conducted to compare the effects on ED incidence of a preoperative visit to the operating room (PVOR) to the administration of propofol at the end of sevoflurane anesthesia on children (3-6 yrs) and routine care (sevoflurane only). Both the PAED scale and Aono's four-point scale were used to assess ED. The results showed a significantly higher incidence of ED in the group that received routine care compared to the PVOR group the propofol group $(P<0.05)$. There was, however, no significant difference in the incidence of ED between the PVOR group and the group that received Propofol.

\subsection{Acupuncture}

Alternative medical interventions to prevent or treat ED have also been investigated. A prospective, double-blinded randomized clinical study published in 2016 investigated the effect of anxiety-reducing acupuncture of the "Heart 7" (HT7) point, located on the ulnar side of the wrist by bilateral electrical, stimulation [60]. This intervention was found to reduce the incidence of ED, consistent with the known link between anxiety and delirium. In 2018, the results of a similar trial by the same group of researchers showed that unilateral electrical stimulation of the same point (HT7) did not affect the incidence of ED [61].

\subsection{The effect of intraoperative monitoring on ED prediction}

A prospective, predictive study was conducted to investigate if changes of EEG monitored intraoperatively could predict the incidence of ED in children (1-6 yrs) under sevoflurane anesthesia. Emergence Delirium was measured using the Cole 5-point scale. This study found a positive correlation between intraoperative EEG changes and ED incidence [62]. Another prospective, observational cohort study investigated a possible correlation between EEG epileptiform discharges during induction of anesthesia in children (0.5-8 yrs) undergoing elective surgery and the incidence of ED. The PAED scale was employed. One type of discharge, the interictal spikes, were associated with ED $(P=0.004)$ [62]. The variety of drugs administered to patients was not accounted for. Koch and colleagues [63] performed a study to evaluate whether the oc- 
currence and the duration of burst suppression on EEG during general anesthesia are related to subsequent development of ED. Using the PAED scale, the results indicated that there was no significant difference in burst suppression between children who developed ED and those who did not. Further studies are needed to determine the effects of intraoperative monitoring on ED - e.g. using intraoperative EEG or heart rate variability.

\subsection{Preoperative fasting and ED}

Khanna and colleagues [64] conducted a prospective observational study to investigate if there was any correlation between the length of preoperative fasting and the incidence of ED in children (2-6 yrs). Emergence delirium was assessed using the PAED scale with a significant positive correlation being found between preoperative fasting and the PAED score at 15 and 25 minutes postoperatively $(P=0.02)$.

\subsection{Management of established EA/ED}

ED is a self-limiting condition usually lasting less than 10 min. Hence, the mainstay of its treatment is to eliminate any causative factor(s) (pain, anxiety, PONV, the presence of invasive devices, and the lack of parents). So far, only one randomized controlled trial has been published on this issue. Funk and colleagues compared the effects of physostigmine and placebo on ED in preschool children and failed to show any effect [65]. Most practitioners prefer to use a sedative (e.g. propofol, ketamine, midazolam, clonidine, or dexmedetomidine) and/or opioids (fentanyl, morphine). Dexmedetomidine is increasingly considered the most appropriate prophylactic medication given its intrinsic analgesic and sedative properties to prevent ED [2]. When PONV is a problem many anesthetists chose clonidine as it is known to reduce PONV in addition to providing analgesia. Much more work is warranted on these issues.

\section{Conclusions and thoughts for the future}

The incidence of ED amongst young children is too high and carries the potential for self-inflicted harm, as well as the possibility of long-term sequelae, hitherto unknown. Despite major advancements in the neuroscience of anesthesiology, the pathogenesis of ED has yet to be sufficiently elucidated. Although several risk factors for ED are known (e.g. volatile inhalation anesthetics, age, gender, type of surgery), and preventive measures have been sought and found (e.g. TIVA, $\alpha_{2}$-agonists), there is an urgent need for future research to fill in gaps of knowledge. Administration of melatonin, for instance, has shown promising results in reducing ED incidence, but further research is needed to properly validate its efficacy. A consensus within the research community on the implementation of a standardized and validated screening tool for ED would aid in comparing research data and results, which today is hampered by the use of a broad range of scales. The PAED scale is the most commonly used and validated screening tool developed; however, the use of the PAED scale poses a challenge when it comes to distinguishing ED from pain and anxiety, especially in the youngest children, and in those with mental retardation and other challenges. To improve the assessment of ED incidence, Mason [60] has suggested implementing a preoperative PAED score to assess a baseline for each individual, which may be used for postoperative comparison. Hopefully, the future will bring novel agents that may remove ED in pediatric anesthesia.

\subsection{Limitations of this review}

In this review, we aimed to present the most recent research in the field of postoperative pediatric ED. Our search scope was thus restricted. In doing so we may have excluded relevant studies published before 2018. However, the scientific quality of more recent studies may be higher compared to older ones. Moreover, recent studies have better taken into account pain as a confounding issue when assessing ED.

\section{AUTHOR CONTRIBUTIONS}

All authors are responsible for conception, drafting, revision and acceptance of the final manuscript.

\section{ACKNOWLEDGMENT}

I would like to express my gratitude to all those who helped me during the writing of this manuscript.

\section{FUNDING}

No external funding received.

\section{CONFLICT OF INTEREST}

The authors declare that they have no conflict of interest.

\section{REFERENCES}

[1] Malarbi S, Stargatt R, Howard K, Davidson A. Characterizing the behavior of children emerging with delirium from general anesthesia. Paediatric Anaesthesia. 2011; 21: 942-950.

[2] Mason KP. Paediatric emergence delirium: a comprehensive review and interpretation of the literature. British Journal of Anaesthesia. 2017; 118: 335-343.

[3] Vlajkovic GP, Sindjelic RP. Emergence delirium in children: many questions, few answers. Anesthesia \& Analgesia. 2007; 104: 84-91.

[4] Sikich N, Lerman J. Development and psychometric evaluation of the pediatric anesthesia emergence delirium scale. Anesthesiology. 2004; 100: 1138-1145.

[5] Ringblom J, Wåhlin I, Proczkowska M. A psychometric evaluation of the pediatric anesthesia emergence delirium scale. Paediatric Anaesthesia. 2018; 28: 332-337.

[6] Aono J, Ueda W, Mamiya K, Takimoto T, Manabe M. Greater incidence of delirium during recovery from sevoflurane anesthesia in preschool boy. Anesthesiology. 1997; 87: 1298-1300.

[7] Bajwa SA, Costi D, Cyna AM. A comparison of emergence delirium scales following general anesthesia in children. Paediatric Anaesthesia. 2010; 20: 704-711.

[8] Tandon M, Singh A, Saluja V, Dhankhar M, Pandey CK, Jain P. Validation of a new "objective pain score" vs. "numeric rating scale" for the evaluation of acute pain: a comparative study. Anesthesia and Pain Medicine. 2016; 6: e32101

[9] Sessler CN, Gosnell MS, Grap MJ, Brophy GM, O’Neal PV, Keane KA, et al. The richmond agitation-sedation scale: validity and reliability in 
adult intensive care unit patients. American Journal of Respiratory and Critical Care Medicine. 2002; 10: 1338-1344.

[10] Cole JW, Murray DJ, McAllister JD, Hirshberg GE. Emergence behaviour in children: defining the incidence of excitement and agitation following anaesthesia. Paediatric Anaesthesia. 2002; 12: 442-447.

[11] Merkel SI, Voepel-Lewis T, Shayevitz JR, Malviya S. The FLACC: a behavioral scale for scoring postoperative pain in young children. Pediatric Nursing. 1997; 23: 293-297.

[12] McGrath PJ, Johnson G, Goodman JT, Dunn J, Chapman J. CHEOPS: a behavioral scale rating postoperative pain in children. In: Fields HL, Dubner R, Cervero F (eds). Advances in pain research and therapy (pp. 395-402). New York: Raven Press. 1985.

[13] Somaini M, Engelhardt T, Fumagalli F, Ingelmo PM. Emergence delirium or pain-how to distinguish between the two in young children: a retrospective analysis of observational studies. British Journal of Anaesthesia. 2016; 116: 377-383.

[14] Kanaya A, Kuratani N, Satoh D, Kurosawa S. Lower incidence of emergence agitation in children after propofol anesthesia compared with sevoflurane: a meta-analysis of randomized controlled trials. Journal of Anesthesia. 2014; 28: 4-11.

[15] Costi D, Cyna AM, Ahmed S, Stephens K, Strickland P, Ellwood J, et al. Effects of sevoflurane versus other general anaesthesia on emergence agitation in children. Cochrane Database of Systematic Reviews. 2014; 12: CD007084.

[16] Cohen IT, Finkel JC, Hannallah RS, Hummer KA, Patel KM. Rapid emergence does not explain agitation following sevoflurane anaesthesia in infants and children: a comparison with propofol. Paediatric Anaesthesia. 2003; 13: 63-67.

[17] Oh A, Seo K, Kim S, Kim C, Kim H. Delayed emergence process does not result in a lower incidence of emergence agitation after sevoflurane anesthesia in children. Acta Anaesthesiologica Scandinavica. 2005; 49: 297-299.

[18] Kocaturk O, Keles S. Recovery characteristics of total intravenous anesthesia with propofol versus sevoflurane anesthesia: a prospective randomized clinical trial. Journal of Pain Research. 2018; 11: 1289-1295.

[19] Voepel-Lewis T, Malviya S, Tait AR. A prospective cohort study of emergence agitation in the pediatric postanesthesia care unit. Anesthesia and Analgesia. 2003; 96: 1625-1630.

[20] Badawy AA, Kasem SA, Rashwan D, Al Menesy T, Adel G, Mokhtar $\mathrm{AM}$, et al. The role of Gabapentin oral solution in decreasing desflurane associated emergence agitation and delirium in children after stabismus surgery, a prospective randomized double-blind study. BMC Anesthesiology. 2018; 18: 73.

[21] Rosen HD, Mervitz D, Cravero JP. Pediatric emergence delirium: Canadian Pediatric Anesthesiologists' experience. Pediatric Anesthesia. 2016; 26: 207-212.

[22] Huett C, Baehner T, Erdfelder F, Hoehne C, Bode C, Hoeft A, et al. Prevention and therapy of pediatric emergence delirium: a national survey. Paediatric Drugs. 2017; 19: 147-153.

[23] Costi D, Ellwood J, Wallace A, Ahmed S, Waring L, Cyna A. Transition to propofol after sevoflurane anesthesia to prevent emergence agitation: a randomized controlled trial. Paediatric Anaesthesia. 2015; 25: 517-523.

[24] Abbas MS, El-Hakeem EEA, Kamel HE. Three minutes propofol after sevoflurane anesthesia to prevent emergence agitation following inguinal hernia repair in children: a randomized controlled trial. Korean Journal of Anesthesiology. 2019; 72: 253-259.

[25] Wu X, Cao J, Shan C, Peng B, Zhang R, Cao J, et al. Efficacy and safety of propofol in preventing emergence agitation after sevoflurane anesthesia for children. Experimental and Therapeutic Medicine. 2019; 17: 31363140.

[26] Aouad MT, Yazbeck-Karam VG, Nasr VG, El-Khatib MF, Kanazi GE, Bleik JH. A single dose of propofol at the end of surgery for the prevention of emergence agitation in children undergoing strabismus surgery during sevoflurane anesthesia. Anesthesiology. 2007; 107: 733-738.

[27] Lee CJ, Lee SE, Oh MK, Shin CM, Kim YJ, Choe YK, et al. The effect of propofol on emergence agitation in children receiving sevoflurane for adenotonsillectomy. Korean Journal of Anesthesiology. 2010; 59: 75-81.

${ }^{[28]}$ Breschan C, Platzer M, Jost R, Stettner H, Likar R. Midazolam does not reduce emergence delirium after sevoflurane anesthesia in children. Paediatric Anaesthesia. 2007; 17: 347-352.
[29] Hosny MR, Saleh AN, Abdelaal WA, Rabie TM. Effect of iv midazolam premedication on the recovery of pediatric patients after isoflurane anesthesia for cochlear implant surgery. The Open Anesthesia Journal. 2019; 13: 47-52.

[30] Cho EJ, Yoon SZ, Cho JE, Lee HW. Comparison of the effects of 0.03 and $0.05 \mathrm{mg} / \mathrm{kg}$ midazolam with placebo on prevention of emergence agitation in children having strabismus surgery. Anesthesiology. 2014; 120: 1354-1361.

[31] Khan A, Ali A, Farooq U, Taqi M. A comparison of midazolam and propofol in prevention of sevoflurane induced emergence agitation in children undergoing inguinal herniotomy and circumcision. Pakistan Journal of Medical \& Health Sciences. 2019; 13: 379-381.

[32] Tan Y, Shi Y, Ding H, Kong X, Zhou H, Tian J. M-Opioid agonists for preventing emergence agitation under sevoflurane anesthesia in children: a meta-analysis of randomized controlled trials. Paediatric Anaesthesia. 2016; 26: 139-150.

[33] Choi EK, Lee S, Kim WJ, Park S. Effects of remifentanil maintenance during recovery on emergence delirium in children with sevoflurane anesthesia. Paediatric Anaesthesia. 2018; 28: 739-744.

[34] Zhao N, Wu Y, Yu C. Effect of intravenous nalbuphine on emergence agitation in children undergoing dental surgery under sevoflurane anesthesia. International Journal of Clinical and Experimental Medicine. 2018; 11: 10215-10222.

[35] Keles S, Kocaturk O. The effect of oral dexmedetomidine premedication on preoperative cooperation and emergence delirium in children undergoing dental procedures. BioMed Research International. 2017; 2017: 6742183.

[36] Keles S, Kocaturk O. Comparison of oral dexmedetomidine and midazolam for premedication and emergence delirium in children after dental procedures under general anesthesia: a retrospective study. Drug Design, Development and Therapy. 2018; 12: 647-653.

[37] Sajid B, Mohamed T, Jumaila M. A comparison of oral dexmedetomidine and oral midazolam as premedicants in children. Journal of Anaesthesiology, Clinical Pharmacology. 2019; 35: 36-40.

[38] Sharma K, Kumar M, Gandhi R. Effect of single-dose dexmedetomidine on intraoperative hemodynamics and postoperative recovery during pediatric adenotonsillectomy. Anesthesia, Essays and Researches. 2019; 13: 63-67.

[39] Shi M, Miao S, Gu T, Wang D, Zhang H, Liu J. Dexmedetomidine for the prevention of emergence delirium and postoperative behavioral changes in pediatric patients with sevoflurane anesthesia: a double-blind, randomized trial. Drug Design, Development and Therapy. 2019; 13: 897-905.

[40] Li H, Zhang L, Shi M, Yang S, Li S, Gao S. Impact of dexmedetomidine on pediatric agitation in the postanesthesia care unit. Journal of PeriAnesthesia Nursing. 2018; 33: 53-57.

[41] Rao Y, Zeng R, Jiang X, Li J, Wang X. The effects of dexmedetomidine on emergence agitation or delirium in children after anesthesia-a systematic review and meta-analysis of clinical studies. Frontiers in Pediatrics. 2020; 8: 329 .

[42] Hong B, Jung C, Jo Y, Youn S, Kim Y, Chung W, et al. Postoperative pain relief by ultrasound- guided brachial plexus block reduces paediatric emergence delirium. Anesthesia and Pain Medicine. 2019; 14: 280-287.

[43] Makkar JK, Kuberan A, Singh PM, Gopinath AM, Jain K, Singh J, et al. Effect of peribulbar block on emergence agitation in children undergoing strabismus surgery under desflurane anaesthesia. Southern African Journal of Anaesthesia and Analgesia. 2018; 24: 140-144.

[44] Hu Z, Ye W, Hu Y, Wu Y, Zhu Z, Jin X. Retrobulbar dexmedetomidine in pediatric vitreoretinal surgery eliminates the need for intraoperative fentanyl and postoperative analgesia: a randomized controlled study. Indian Journal of Ophthalmology. 2019; 67: 922-927.

[45] Abdulatif M, Ahmed A, Mukhtar A, Badawy S. The effect of magnesium sulphate infusion on the incidence and severity of emergence agitation in children undergoing adenotonsillectomy using sevoflurane anaesthesia. Anaesthesia. 2013; 68: 1045-1052.

[46] Kain ZN, MacLaren JE, Herrmann L, Mayes L, Rosenbaum A, Hata J, et al. Preoperative melatonin and its effects on induction and emergence in children undergoing anesthesia and surgery. Anesthesiology. 2009; 111: 44-49.

[47] Chen J, Jia J, Liu T, Qin M, Li W. Comparison of the effects of 
dexmedetomidine, ketamine, and placebo on emergence agitation after strabismus surgery in children. Canadian Journal of Anaesthesia. 2013; 60: 385-392.

[48] Jalili S, Esmaeeili A, Kamali K, Rashtchi V. Comparison of effects of propofol and ketofol (Ketamine-Propofol mixture) on emergence agitation in children undergoing tonsillectomy. African Health Sciences. 2019; 19: 1736-1744.

[49] Takzare A, Sadrossadat H, Sanatkar M, Roustaie S, Goudarzi M. Effect of ondansetron on post-anesthesia delirium in sevoflurane-anesthetized children undergoing eye surgery in Farabi hospital in 2015. International Journal of Pharmaceutical Research. 2019; 11: 1781-1785.

[50] Ji JY, Park JS, Kim JE, Kim DH, Chung JH, Chun HR, et al. Effect of esmolol and lidocaine on agitation in awake phase of anesthesia among children: a double-blind, randomized clinical study. Chinese Medical Journal. 2019; 132: 757-764.

[51] Lee SJ, Cho CK. Comparison of emergence agitation between succinylcholine and rocuronium/sugammadex in adults following closed reduction of a nasal bone fracture: a prospective randomized trial. BMC Anesthesiology. 2019; 19; 228.

[52] Kain ZN, Mayes LC, Caldwell-Andrews AA, Karas DE, McClain BC. Preoperative anxiety, postoperative pain, and behavioral recovery in young children undergoing surgery. Pediatrics. 2006; 118: 651-658.

[53] Kain ZN, Caldwell-Andrews AA, Maranets I, McClain B, Gaal D, Mayes LC, et al. Preoperative anxiety and emergence delirium and postoperative maladaptive behaviors. Anesthesia and Analgesia. 2004; 99: 1648-1654.

[54] Berghmans JM, Poley M, Weber F Van De Velde M, Adriaenssens P, Klein J, Himpe D, et al. Does the child behavior checklist predict levels of preoperative anxiety at anesthetic induction and postoperative emergence delirium? A prospective cohort study. Minerva Anestesiologica. 2015; 81: $145-156$

[55] Byun S, Song S, Kim JH, Ryu T, Jeong MY, Kim E. Mother's recorded voice on emergence can decrease postoperative emergence delirium from general anaesthesia in paediatric patients: a prospective randomised controlled trial. British Journal of Anaesthesia. 2018; 121: 483-489.

[56] Yang YY, Zhang MZ, Sun Y, Peng ZZ, Liu PP, Wang YT, et al. Effect of recorded maternal voice on emergence agitation in children undergoing bilateral ophthalmatic surgery: a randomised controlled trial. Journal of Paediatrics and Child Health. 2020; 56: 1402-1427.

[57] Dwairej D, Obeidat H, Khalaf I. The effectiveness of video distraction on children preoperative anxiety: an integrative literature review. Open
Journal of Nursing. 2018; 3: 171-187.

[58] Stewart B, Cazzell MA, Pearcy T. Single-blinded randomized controlled study on use of interactive distraction versus oral midazolam to reduce pediatric preoperative anxiety, emergence delirium, and postanesthesia length of stay. Journal of PeriAnesthesia Nursing. 2019; 34: 567-575.

[59] Zhong Q, Qu X, Xu C. Effect of preoperative visiting operation room on emergence agitation in preschool children under sevoflurane anesthesia. International Journal of Pediatric Otorhinolaryngology. 2018; 104: 3235 .

[60] Hijikata T, Mihara T, Nakamura N, Miwa T, Ka K, Goto T. Electrical stimulation of the heart 7 acupuncture site for preventing emergence agitation in children. European Journal of Anaesthesiology. 2016; 33: 535-542.

[61] Nakamura N, Mihara T, Hijikata T, Goto T, Ka K. Unilateral electrical stimulation of the heart 7 acupuncture point to prevent emergence agitation in children: a prospective, double-blinded, randomized clinical trial. PLoS ONE. 2019; 13: e0204533.

[62] Jang Y, Jeong S, Kim S, Song I, Lee J, Kim J, et al. The efficacy of intraoperative eeg to predict the occurrence of emergence agitation in the postanesthetic room after sevoflurane anesthesia in children. Journal of PeriAnesthesia Nursing. 2018; 33: 45-52.

[63] Koch S, Stegherr AM, Rupp L, Kruppa J, Prager C, Kramer S, et al. Emergence delirium in children is not related to intraoperative burst suppression-prospective, observational electrography study. BMC Anesthesiology. 2019; 19: 146.

[64] Khanna P, Saini K, Sinha R, Nisa N, Kumar S, Maitra S. Correlation between duration of preoperative fasting and emergence delirium in pediatric patients undergoing ophthalmic examination under anesthesia: a prospective observational study. Pediatric Anesthesia. 2018; 28: 547551.

[65] Funk W, Hollnberger H, Geroldinger J. Physostigmine and anesthesia emergence delirium in preschool children: a randomized blinded trial. European Journal of Anaesthesiology. 2008; 25: 37-42.

How to cite this article: Oda Grung Grotmol, Narththahi Nesarajah, Tom Giedsing Hansen. Postoperative emergence delirium in children: a narrative review of recent publications. Signa Vitae. 2021;17(3):10-20. doi:10.22514/sv.2021.057. 